\title{
A ESTESIA ÀS AVESSAS NA ERA DA REPRODUTIBILIDADE TÉCNICA: UMA LEITURA BENJAMINIANA DE "SALÒ OU OS 120 DIAS DE SODOMA"
}

\author{
Alice Vieira Barros \\ Universidade Federal de Minas Gerais, Belo Horizonte, Brasil \\ alicevieirabarros@gmail.com
}

\begin{abstract}
Resumo
Este artigo se propõe a analisar o filme "Salò ou os 120 dias de Sodoma" (1975) quanto à técnica cinematográfica e quanto ao conteúdo de crítica e denúncia política do regime fascista, tomando como base o ensaio "A obra de arte na era de sua reprodutibilidade técnica" (1936) do filósofo alemão Walter Benjamin e seus comentários acerca da estetização da política no fascismo. Para melhor compreender como a violência do regime fascista é retratada no filme, lançou-se mão do texto "A doutrina do fascismo" (1932), escrito conjuntamente pelo filósofo Giovanni Gentile - um dos teóricos do fascismo e pelo ditador Benito Mussolini. Por fim, para analisar como o longa de certa forma escancara singularidades dos regimes totalitários, recorreu-se às reflexões tecidas pela filósofa alemã Hannah Arendt acerca do julgamento do nazista Eichmann na Casa de Justiça de Jerusalém presentes no livro "Eichmann em Jerusalém: um relato sobre a banalidade do mal" (publicado pela primeira vez em 1963).

Palavras-chave

Pasolini. Salò. Cinema. Reprodutibilidade técnica. Fascismo. Benjamin.
\end{abstract}

\begin{abstract}
This article aims to analyze the movie "Salò o le 120 giornate di Sodoma" (1975), its film technique and its critical and political content about the denunciation of the fascist regime, based on the essay "A obra de arte na era de sua reprodutibilidade técnica" (1936) from german philosopher Walter Benjamin and his comments about the aestheticization of politics in Fascism. To better understand how violence of the fascist regime is portrayed on the movie, it was employed the text "La doctrine du fascisme" (1932), written jointly by the philosopher Giovanni Gentile - one of the fascists theorists - and by the dictator Benito Mussolini. Finally, to analyze how the film somehow shows singularities of totalitarian regimes, it appealed to the reflections made by german philosopher Hannah Arendt about Eichmann Nazi trial in the Jerusalem House of Justice extracted from the book "Eichmann em Jerusalém: um relato sobre a banalidade do mal" (published for the first time in 1963).
\end{abstract}

Key words

Pasolini. Salò. Cinema. Technical reproduction. Fascism. Benjamin.

\section{Introdução}

Lançado em 1975 e dirigido pelo diretor italiano Pier Paolo Pasolini, "Salò ou os 120 dias de Sodoma" consagrou-se como um dos filmes mais perturbadores da 
história do cinema. O longa se passa na região da Itália Setentrional, durante a ocupação nazi-fascista (1944-1945) e retrata um grupo de dirigentes fascistas que promove o rapto de rapazes e moças para que se tornem objetos de experiência de todos os seus fetiches sexuais, vivendo sob regime de exceção numa casa isolada sem nenhum contato com o restante do mundo.

Esta situação ficcional que conduz o desenvolvimento do filme parece absurda, não obstante, poder-se-ia dizer, grosso modo, que seu caráter arbitrário - até caricato, em sua natureza paroxística e escatológica - não entra em contradição com a natureza de um regime que se fundamenta filosoficamente numa noção de Estado como entidade metafísica e absoluta e que também se propõe a constituir uma filosofia de vida, afinal, em texto de co-autoria com Benito Mussolini ${ }^{1}$, o filósofo Giovanni Gentile afirma:

\footnotetext{
"Il n'existe pas une conception de l'État qui ne soit aussi fondamentalement une conception de la vie: que ce soit une philosophie ou une institution, un système d'idées qui se développe selon les données de la logique ou se concentre en une vision ou en une croyance, elle est toujours, au moins virtuellement, une conception organique du monde". ${ }^{2}$ (TRAVERSO, 2001, p. 124).
}

Até que ponto é possível considerar tais afirmações como proposições filosóficas e tomar o texto como uma genuína Filosofia do Direito ou do Estado é difícil precisar, mas o caráter de justificação ideológica de um regime totalitário que entende o Estado como uma vontade ética universal não tarda a se manifestar no texto. É preciso que ele seja lido cautelosamente, para que não se aceite o hegelianismo distorcido de Gentile como uma formulação válida e para que não se esqueça que se trata de uma tentativa de se construir uma justificação ideológica, bem como uma fórmula sedutora e propagandística para um regime totalitário que prima pela barbárie. Ademais, o texto tem uma pretensão universalizante bastante evidente - é preciso que se observe que,

\footnotetext{
${ }^{1}$ GENTILE, Giovanni; MUSSOLINI, Benito. La Doctrine du fascisme. In: TRAVERSO, Enzo. Le totalitarisme: le XXe siècle en débat. Paris: Seuil, 2001.

${ }^{2}$ Não existe uma concepção de Estado que não seja também fundamentalmente uma concepção da vida: que seja uma filosofia ou instituição, um sistema de idéias que se desenvolve de acordo com o que é dado pela lógica ou se concentra em uma visão ou em uma crença, ela é sempre, ao menos virtualmente, uma concepção orgânica do mundo (tradução nossa).
} 
diferentemente do regime hitlerista alemão, o regime fascista italiano era mais perigosamente exportável ${ }^{3}$.

Não obstante os riscos de leitura, o texto de Gentile e Mussolini é um bom ponto de partida para este artigo, na medida em que demonstra como o fascismo, mais do que uma filosofia do Estado como um absoluto e uma encarnação metafísica, tinha uma pretensão universalizante de atingir cada esfera da experiência dos cidadãos, de modo a se constituir como uma filosofia de vida. Assim, os esdrúxulos fetiches sexuais dos dirigentes fascistas de Salò, aparecem - para o horror do espectador - como uma possível dimensão do regime, pois, no fascismo, a máxima "tudo é política" é altamente eficaz. Num regime que se propõe a um domínio total, não há uma clara separação entre a esfera pública e a privada - tudo parece estar dominado pela ideologia fascista e pelas práticas fascistas. Submeter e humilhar sexualmente um grupo de jovens, para um regime de terror, ainda é da ordem do político. Talvez isso torne Salò uma experiência estética (se é que ainda se pode transitar pelo campo da estesia num referente dessa natureza) aterradora.

O enredo de Salò revela-se imagética e plasticamente como um teste de qual o limite da capacidade humana de observação: o espectador sente-se um voyeur às avessas, como se tivesse as pálpebras forçosamente levantadas a fim de que resista durante todo o filme às cenas explícitas de tortura e abuso (e como se ele mesmo fosse vítima de uma violência aterradora) - violência, diga-se de passagem, tão intensa, tão desesperadora, tão arbitrária, que por vezes parece inverossímil.

Um detalhe bastante curioso é a já mencionada arbitrariedade da situação apresentada: como conceber que um grupo de jovens seja subitamente raptado para atender às necessidades sexuais sádicas de um repulsivo grupo de dirigentes fascistas? Ainda que se mantivesse o horror da situação, seria mais cômodo para o espectador encontrar uma motivação por trás do ocorrido. Em outras palavras, o filme se tornaria talvez mais digerível se se soubesse que há uma motivação político-ideológica (ainda que sórdida) para o tratamento dado aos jovens italianos raptados. No entanto, ela não se revela em nenhum momento no filme. Com exceção de um adolescente que é

\footnotetext{
${ }^{3} \mathrm{O}$ regime hitlerista, talvez o exemplo paroxístico de um regime totalitário, era menos exportável para o mundo do que o fascismo mussoliniano, devido à ênfase na questão da raça ariana e ao entendimento da necessidade de um espaço vital para a Alemanha. Ao menos em seu início, o movimento fascista italiano não dava tanta ênfase à questão racial.
} 
apresentado como "de família subversiva", não há um aprofundamento nas histórias particulares dos jovens para que se encontre alguma explicação para seu rapto (talvez até porque não haja particularismos possíveis num regime que aspira à dominação da totalidade da vida humana). Tratar-se-ia de anti-semitismo? De punição por atividades anti-fascistas? Teriam cometido algum crime para os dirigentes? $O$ filme não permite precisar. Trata-se, apenas, do desejo imperativo dos dirigentes fascistas. Isto torna a situação ainda mais incômoda e possibilita um interessante questionamento acerca da natureza dos regimes totalitários.

Sobre a arbitrariedade da situação descrita no filme, é interessante traçar um ponto de tangência com o que a filósofa Hannah Arendt descreve em seu livro "Eichmann em Jerusalém" (livro em que, numa mescla de jornalismo político e filosofia, narra o julgamento do nazista Adolf Eichmann em Jerusalém, após seu rapto na argentina arquitetado pelo governo israelense).

Ao refletir acerca da efetiva culpa de Eichmann nas atividades da Solução Final, Arendt relata que os juízes da corte de Jerusalém

(...) começaram explicando que havia duas categorias de judeus nos campos, os chamados "judeus em transporte" (Transportjuden), que constituíam o grosso da população e que nunca haviam cometido um crime, mesmo aos olhos dos nazistas, e os judeus "sob custódia" (Schutzhaftjuden), mandados para os campos de concentração alemães por alguma transgressão e que, sob o princípio totalitário de dirigir o terror do regime contra os "inocentes", viviam consideravelmente melhor do que os outros mesmo quando mandados para o Leste a fim de tornar judenrein os campos de concentração do Reich. (Nas palavras da sra. Raja Jagan, uma excelente testemunha sobre Auschwitz, esse era "o grande paradoxo de Auschwitz. Os que eram capturados cometendo algum crime eram mais bem tratados que os outros": Não ficavam sujeitos à seleção e, como regra, sobreviveram.) $(. . .)^{4}$

Paradoxos desta natureza, não obstante as inúmeras diferenças entre os regimes totalitários do século XX, não eram exclusividade da Alemanha. Mesmo na Rússia soviética essas curiosas situações estavam presentes. Nesta matéria, é impossível não

\footnotetext{
${ }^{4}$ ARENDT, Hannah. Eichmann em Jerusalém: um relato sobre a banalidade do mal. São Paulo: Companhia das Letras, 1999.
} 
lembrar dos Processos de Moscou, em que as próprias vítimas assumiam a culpa por crimes que não tinham cometido. A situação parece absurda, mas é possível especular que era menos doloroso morrer - se é que "uma morte menos dolorosa" pode ser uma proposição válida - reconhecendo ter falhado para o regime do qual era parte integrante, e, portanto, ainda sentir-se, de certa forma, parte do regime, do que assumir que não havia de fato nenhuma culpa e, deste modo, contemplar, ao fim da vida, a tragicidade de sua existência enquanto um indivíduo moderno solitário e atomizado.

Não obstante as inúmeras diferenças entre os regimes hitlerista e mussoliniano, o exemplo dado por Arendt serve muito bem para delinear como se conduzem os regimes totalitários em que "l'État s'est transformé et possède la même conscience, la même volonté que le peuple"5 (em tradução nossa: o Estado se transforma e possui a mesma consciência, a mesma vontade que o povo). Seria mais cômodo para o espectador de Salò se a situação que é exibida - considerando seu caráter altamente arbitrário já mencionado - fosse totalmente destoante das proposições do regime fascista - mas, pelo contrário, se mostra altamente coerente para um regime em que o Estado constitui uma entidade metafísica. Ou, conforme já foi dito, o filme se tornaria mais palatável se fosse possível encontrar alguma culpa nos jovens (ainda que apenas sobre a ótica fascista da culpa). Analogamente, seria mais fácil pensar o mal nas experiências políticas totalitárias do século XX se o Führer confinasse os judeus a fim de explorar seu trabalho escravo - a narrativa do horror tornar-se-ia talvez mais palatável porque haveria um motivo (mesmo que extremamente desprezível) de natureza econômica. No entanto, se o Holocausto levou à morte de seis milhões de judeus, a exploração do trabalho de um povo não passava pelos últimos objetivos da Solução Final. Nesse sentido, o filme de Pasolini, com toda a sua nauseante e terrível violência, metaforiza muito bem as deambulações dos regimes nazi-fascistas. Onde impera o terror e o totalitarismo, a violência não precisa de um porquê.

\section{A barbárie na era da reprodutibilidade técnica}

Entenda-se o regime de "exceção" vivido pelos personagens de Salò em seu sentido ambivalente - tal como empregado pelo filósofo italiano Giorgio Agamben:

\footnotetext{
${ }^{5}$ GENTILE, Giovanni; MUSSOLINI, Benito. Op. cit.
} 
(...) Como sempre foi exposto pela teoria, a excepção funciona formalmente como uma inversão do exemplo, quase como um $<<$ antiexemplo $>>$. (...) De facto, Agamben coloca os dois lugares numa posição simétrica mais do que opositiva, funcionando como um quiasmo: a exceção como exclusão inclusiva (incluindo o que se encontra posto por fora) e o exemplo como inclusão exclusiva (ou seja, exibindo o que se encontra por dentro). (VECCHI, 2010, pág.20).

Cabe destacar a ambivalência da ideia de exceção porque, conquanto estivessem isolados de qualquer contato com o mundo externo e vivendo sob um regime de leis escrito e instituído pelos fascistas, a verdade é que a conjuntura externa não era muito diferente, estando a Itália e vários países marcados pelos regimes totalitários, cujo terror quase ia adquirindo aspecto de "normalidade" portanto, só emblematicamente representa esta exceção sendo levada à sua máxima potência. Afinal, não obstante a vasta produção intelectual ${ }^{7}$ da primeira metade do século XX que tornou palatável a ideia de um Estado totalitário, o totalitarismo nazista e fascista calcava-se, sobretudo, em práticas e ações - a saber, de natureza coercitiva e violenta.

Esse artigo tenciona, a partir das considerações tecidas pelo filósofo Walter Benjamin em seu texto "A obra de arte na era de sua reprodutibilidade técnica" (1935/1936), avaliar o filme de Pasolini quanto à técnica cinematográfica e seu conteúdo de crítica e denúncia política a partir da leitura do fascismo construída por Benjamin, que disserta, ao final de seu texto, sobre a principal singularidade dos regimes fascistas, a saber, a "estetização da política":

Na época de Homero, a humanidade oferecia-se em espetáculo aos deuses olímpicos; agora, ela se transforma em espetáculo para si mesma. Sua

\footnotetext{
${ }^{6}$ Entenda-se "normalidade" neste contexto apenas metaforicamente, não como sinônimo de "banalidade", para evitar uma imprecisão terminológica que faria com que este ensaio parecesse coadunar com a leitura da filósofa Hannah Arendt sobre o tema, dialogando com o conceito de "banalidade do mal". Vale ressaltar que não é objetivo desse artigo fazer uma leitura hermenêutica da ideia de "totalitarismo".

${ }^{7} \mathrm{O}$ nazismo precisou também de uma história conceitual para que tão rapidamente juristas e médicos integrantes da classe média germânica tenham aderido ao regime. A produção intelectual que tornou possível a ideia de um Estado totalitário conceitualmente é bastante complexa e transita desde o elogio ao heroísmo e à morte guerreira nos escritos de Ernst Jünger até a separação entre a moral e a política na teoria de Carl Schmitt, que afasta da esfera do Estado as noções de "bem" e "mal". Cabe destacar que a extensa lista de intelectuais da época que contribuíram para a história conceitual do Estado totalitário não necessariamente aderiram ao regime, mas, de alguma forma, - mesmo que por uma indevida apropriação posterior pelo regime - tornaram teoricamente possível a defesa de um Estado totalitário ou, ao menos, de um Estado total.
} 
autoalienação atingiu o ponto que lhe permite viver sua própria destruição como um prazer estético de primeira ordem. Eis a estetização da política, como a pratica o fascismo. O comunismo responde com a politização da arte. (BENJAMIN, 1935/1936, pág 34).

Benjamin traça, em seu texto, um panorama de como a reprodutibilidade técnica se instituiu no modelo de produção do sistema capitalista e como a ela se seguiu uma reconfiguração na concepção da arte e do objeto artístico. A reprodutibilidade técnica, tornando tudo passível de cópia e reprodução, retiraria dos objetos artísticos o valor de culto que assumiam na Antiguidade, e, portanto, a produção artística deixa de fundar-se no ritual e as obras perderiam a sua "aura". Cito o conceito de aura tal como entendido por Walter Benjamin:

(...) Em suma, o que é a aura? É uma teia singular, composta de elementos espaciais e temporais: a aparição única de uma coisa distante, por mais perto que ela esteja. Observar, em repouso, numa tarde de verão, uma cadeia de montanhas no horizonte, ou um galho, que projeta sua sombra sobre nós, significa respirar a aura dessas montanhas, desse galho. (BENJAMIN, 1935/1936, pág. 6).

A partir deste conceito de aura, não é difícil inferir que a reprodutibilidade técnica, suprimindo cada vez mais a autenticidade da obra de arte, vai na contramão da aura. A reprodutibilidade técnica destrói a aura e, no modelo de produção industrial que se instaura na Modernidade, tudo é passível de reprodução e produção em massa de acordo com as demandas capitalistas da oferta e da procura. O cinema, como arte cuja reprodutibilidade técnica faz parte do conjunto da produção artística, da filmagem e da montagem, é o auge desse processo. Sobre o método de produção do cinema, Benjamin diz:

(...) A reprodutibilidade técnica do filme tem seu fundamento imediato na técnica de sua produção. Esta não apenas permite, da forma mais imediata, a difusão em massa da obra cinematográfica, como a torna obrigatória. A difusão se torna obrigatória, porque a produção de um filme é tão cara que um consumidor, que poderia, por exemplo, pagar um quadro, não pode mais pagar um filme. (...) (BENJAMIN, 1935/1936, pág 8).

É bastante válido destacar que Benjamin não entende a destruição da aura e a reprodução em massa das obras de arte como um processo necessariamente negativo, mas que serve à reformulação e à ressignificação do que é concebido como arte. $\mathrm{O}$ ponto fulcral estaria em como os detentores do poder político-econômico se apropriariam dos dispositivos que integram a era da reprodutibilidade técnica, para que 
o cinema cumpra um papel reacionário e impeça o desenvolvimento da consciência crítica das massas:

\footnotetext{
Vale para o capital cinematográfico o que vale para o fascismo no geral: ele explora secretamente, no interesse de uma minoria de proprietários, a inquebrantável aspiração por novas condições sociais. Já por essa razão a expropriação do capital cinematográfico é uma exigência prioritária do proletariado. (BENJAMIN, 1935/1936, pág. 22).
}

O cinema representa uma transformação muito significativa na recepção da obra de arte pelo público, diferenciando-se da pintura por não exigir espectadores solitários e contemplativos, mas um público grande, que compense os custos de produção do filme e que reaja coletivamente diante da exposição e movimentação incessante de imagens. Destaco este ponto porque a reação coletiva diante de uma obra de arte, para Benjamin, pode dar-se de duas formas: uma reação progressista e uma reação retrógrada.

Quando se institui uma distância entre o público e uma obra de arte, quanto mais ela tende para o culto, a reação do público tende a ser retrógrada, desfruta-se acrítica e passivamente do que é apresentado, pelo receio de posicionar-se contra aquilo que dispõe de uma carga aurática e ritualística. Isso não implicaria que a arte cinematográfica, cuja produção se funda na reprodutibilidade técnica, demandaria sempre uma reação progressista da parte do público, haja vista que o cinema romperia toda a distância entre o espectador e uma obra de arte. Afinal, a reação do público é uma diante de um filme cômico-grotesco e é outra diante de uma obra de vanguarda.

Benjamin não viveria para vislumbrar até que ponto chegariam os experimentos cinematográficos do século $\mathrm{XX}$ e, se por um lado, fala de uma "estética da guerra" já muito bem descrita no manifesto futurista de Marinetti, muito provavelmente não imaginaria as deambulações de uma estética do horroroso que culminariam num cinema de contracultura como "Pink Flamingos" (1972) - aqui o horror se presta à crítica política e paródica - e em "Salô" (1975) - em que a violência, o escatológico e o sadismo inomináveis se apresentam sem nenhuma restrição. Como pensar na recepção do público diante do delírio estético de Pasolini?

"Salò" não lança mão ostensivamente do discurso irônico para uma revisão crítica do fascismo, mas apresenta imageticamente um conceito de fascismo. Diante das cenas aterradoras de estupro e sadismo e dos desvarios escatológicos, o espectador se 
presta a repetidos choques, até sentir-se completamente anestesiado nas cenas finais de tortura. "Os 120 dias de Sodoma" é um filme bem sucedido, sobretudo, por conseguir em menos de duas horas apresentar toda uma singular - e apavorante - estesia fascista.

Benjamin percebeu muito bem como a prática da estetização da política era um procedimento importante dos regimes fascistas. Tudo nos regimes totalitários de exceção primava pelo espetáculo do horror. As câmaras de gás como um mecanismo de destruição em massa parecem consistir no auge da era da reprodutibilidade técnica. Diante da produção industrial que sobra, a guerra, a "revolta da técnica, que cobra em "material humano" o que lhe foi negado pela sociedade. Em vez de usinas energéticas, ela mobiliza energias humanas, sob a forma dos exércitos.” (BENJAMIN, 1935/1936, pág. 33).

Não por acaso todos os dirigentes fascistas de "Salò" fazem referência a excertos literários e lançam mão de uma linguagem insistentemente culta e adornada. Benjamin percebeu muito bem que a ideologia fascista demandava uma tentativa de se estetizar a política, dando legitimidade à guerra: “(...) Todos os esforços para estetizar a política convergem para um ponto. Esse ponto é a guerra.” (...) (BENJAMIN, 1935/1936, pág. 32). Na Alemanha nazista, afinal, parece que a exaltação do heroísmo guerreiro de Ernst Jünger e a proposição de uma "mobilização total" de fato funcionaram para a juventude alemã. Nos regimes nazi-fascistas, a guerra se tornou legítima e admirável ${ }^{8}$.

Se a guerra deixa de ser antiestética - como defende Marinetti no "Manifesto Futurista" -, e torna-se uma sinfonia dócil do triunfo do progresso, a destruição humana transforma-se, como enuncia Benjamin, num "prazer estético de primeira ordem”. A ideologia do progresso e do futuro mostra-se, assim, extremamente problemática e conivente com o discurso fascista, pois, ao defender que a guerra é bela porque "funda a supremacia do homem sob a máquina subjugada", esquece-se de que a reprodutibilidade técnica gradativamente deixou de existir a título de uma supremacia humana, mas antes da própria máquina sob o homem, e que a "metalização do corpo humano" advinha, antes de um procedimento estético, de um processo de reificação pela autoalienação. Embora, com a reprodutibilidade técnica, pareça inconcebível não pensar

\footnotetext{
${ }^{8}$ Cf. Ernst Jünger, $<<$ La mobilization totale $>>$, trad. do alemão por Marc B. de Launay, retirado de $<<$ L'État universel suivi de La mobilisation totale $>>$. Paris: Gallimard, 1990, p. 97-98, 102-115, 136141.
} 
historicamente em termos de "progresso", esta noção processual da passagem do tempo não é meta-histórica e remonta ao primado da razão iniciado no Iluminismo 9 .

É este processo de coisificação do homem que se inicia com a alienação do trabalho desenvolvida nas fábricas durante o período da Revolução Industrial e cuja significação vai se ampliando na medida em que se instaura a era da reprodutibilidade técnica no sistema capitalista até chegar ao auge das duas grandes guerras - em que a era das máquinas transforma-se na era da supremacia das alavancas sob o sangue humano em fluxo, da sinfonia dos tanques de guerra sob os ouvidos humanos, cujo rascunho já havia sido profeticamente idealizado no célebre filme expressionista de Fritz Lang (Metrópolis", de 1927) -, que "Salò" apresenta levado até as últimas consequências.

Em "Os 120 dias de Sodoma”, o discurso fascista mostra toda a sua cosmovisão estética, transformando a degradação humana num terrível espetáculo artístico, para o total horror do espectador ao se deparar com o gigantesco saldo de mortes e desespero tributários de uma teleológica visão de progresso - que ideologicamente talvez tenha atingido seu paroxismo com a defesa do novo e do indivíduo em ação no fascismo italiano ${ }^{10}$ - cujo processo de desenvolvimento almejado sofreu uma enorme fissura com a exterminação massiva de milhões de vidas.

\section{REFERÊNCIAS}

ARENDT, Hannah. Eichmann em Jerusalém: um relato sobre a banalidade do mal. São Paulo: Companhia das Letras, 1999.

BENJAMIN, Walter. A obra de arte na era de sua reprodutibilidade técnica. IN: Magia e Técnica, Arte e Política. Obras escolhidas. São Paulo: Brasiliense, 3. ed., 1987.

GENTILE, Giovanni; MUSSOLINI, Benito. La doctrine du fascisme. In: Benito Mussolini, Oeuvres et discours, t. IX, Flamarion, Paris, 1935, p. 61-91.

JÜNGER, Ernst. La mobilisation totale. Paris: Éditions Gallimard, 1990.

KOSELLECK, Reinhart. Crítica e crise: uma contribuição à patogênese do mundo burguês. Rio de Janeiro: Contraponto, 1999.

\footnotetext{
${ }^{9}$ Cf. KOSELLECK, Reinhart. Crítica e crise: uma contribuição à patogênese do mundo burguês. Rio de Janeiro: Contraponto, 1999.

${ }^{10}$ Veja-se, neste sentido, como a biografia de Mussolini - ou ao menos a mitologia construída para a composição de sua imagem - mostra um homem de movimento e atividade. $\mathrm{O}$ fascismo, como comprova Giovanni Gentile em "La Doctrine du fascisme", para além de uma Filosofia do Estado, tornou-se uma Filosofia de vida.
} 
PASOLINI, Pier Paolo. Saló ou os 120 dias de Sodoma. Alberto Grimaldi, Pier Paolo Pasolini. Itália/França, 1975.

VECCHI, Roberto. A exceção atlântica Pensar a Literatura da Guerra Colonial. Porto: Edições Afrontamento, 2010. p. 20. 